\title{
Livestock Depredation by Carnivores in the Serengeti Ecosystem, Tanzania
}

\author{
Angela Mwakatobe $^{1,2}$, Julius Nyahongo ${ }^{3} \&$ Eivin Røskaft ${ }^{1}$ \\ ${ }^{1}$ Department of Biology, Norwegian University of Science and Technology, NTNU, Trondheim No-7491, \\ Norway \\ ${ }^{2}$ Tanzania Wildlife Research Institute, P. O. Box 661, Arusha, Tanzania \\ ${ }^{3}$ University of Dodoma, P.O. Box 259, Dodoma, Tanzania \\ Correspondence: Eivin Røskaft, Department of Biology, NTNU, Realfagbygget, Trondheim No-7491, Norway. \\ Tel: 47-9065-2883. E-mail: roskaft@bio.ntnu.no
}

Received: June 28, 2013 Accepted: July 17, 2013 Online Published: August 25, 2013

doi:10.5539/enrr.v3n4p46 URL: http://dx.doi.org/10.5539/enrr.v3n4p46

\begin{abstract}
Data for livestock depredation by wild animals were collected in villages outside Serengeti National Park, northern Tanzania. We tested livestock mortality against distance of the villages from the protected area in relation to carnivore species involved, methods used to protect livestock from being depredated and frequency of livestock diseases. The results indicate that distance from the park significantly influenced livestock depredation with the lowest depredation rates in the villages farthest away. Spotted hyena (Crocuta crocuta) was the most destructive wild animal, followed by small carnivores (including baboons) which were most destructive in the medium and far away villages. Methods used to protect livestock from being depredated differed significantly based on the distance from the protected area. Wild animals cause a significant economic loss to households; however, livestock diseases were the main cause of livestock loss in the study area. The highest frequencies of deaths due to diseases were experienced in villages located closest to the protected area. We recommend that all conservation stakeholders support efforts of local communities to improve their enclosures, and develop education programs to improve their livestock husbandry skills. We also recommend that veterinary units be staffed with well-trained personnel, adequate facilities and substantial operational budgets to enable them to adequately function. Also, not only villagers near protected areas, but also any residents, should be helped by veterinary units. Lastly, we recommend an integrated study on livestock and wildlife diseases and their impact on household economies of the local communities.
\end{abstract}

Keywords: livestock depredation, serengeti ecosystem, human-wildlife conflict, wild animals

\section{Introduction}

Human-carnivore conflict is one of the main constraints to biodiversity conservation efforts outside many protected areas (Holmern, Mkama, Muya, \& Røskaft, 2006; Kent, 2011; Lyamuya, Masenga, Fyumagwa, \& Røskaft, 2013; Nyahongo, 2007). The most frequent type of conflict between humans and wild animals in different parts of the world are livestock depredation (Dickman, 2008; Kajembe, Mayeta, Nduwamungu, \& Katani, 2005; Kaswamila, 2009; Nyahongo, 2007; Thirgood, Woodroffe, \& Rabinowitz, 2005) and crop damages (Kajembe, Mayeta, Nduwamungu, \& Katani, 2005; Kaswamila, 2009; Nyahongo, 2007; Sitati, Walpole, \& Leader-Williams, 2003), while human fatalities are another serious consequence of such conflicts (Baldus, 2004; Ikanda, 2009; Kushnir, Leitner, Ikanda, \& Packer, 2010; Løe \& Røskaft, 2004; Packer, Ikanda, Kissui, \& Kushnir, 2005; Quigley \& Herrero, 2005). The co-existence of large carnivores, livestock and humans frequently provoke conflicts threatening the future viability of carnivore populations in African pastoral systems (Ogutu, Bhola, \& Reid, 2005). Increasing human populations and associated increases in the use of natural resources and habitat are in many areas, forcing wildlife to live in close proximity to humans (Ikanda, 2009). Pastoralists keep high numbers of livestock that serve as social capital and a sign of wealth (Hazzah, 2006). According to Ukio (2010), high numbers of livestock require large pieces of land, which are increasingly unavailable due to rapid human population growth and increased land use requirements. In these circumstances, competition arises between wildlife and people for space and food resources (Dickman, 2008; Thirgood, Woodroffe, \& Rabinowitz, 2005). 
Human-wildlife conflict due to predation affects population dynamics of wild carnivores near park boundaries (Kangwana, 1996; Kangwana, 1995; Kolowski \& Holekamp, 2006; Sillero-Zubiri \& Laurenson, 2001). However, according to Ogada (2003), conflict with local people, particularly over depredation of livestock, is a major cause of population decline in carnivores, affecting both protected carnivore populations as well as those living outside of protected areas. Livestock predation is primarily caused by yellow baboons (Papio cynocephalus), leopards (Panthera pardus), lions (Panthera leo) and spotted hyenas (Crocuta crocuta) (Holmern, Mkama, Muya, \& Røskaft, 2006; Ikanda \& Packer, 2008; Kissui, 2008; Kolowski \& Holekamp, 2006; Nyahongo, 2007; Packer, Ikanda, Kissui, \& Kushnir, 2005) in many protected areas as well as outside of protected areas in Tanzania. Black-backed jackals (Canis mesomelas), golden jackals (Canis aureus), olive baboons (Papio anubis), and African wild dogs (Lycaon pictus) are other important predators (Holmern, Mkama, Muya, \& Røskaft, 2006; Holmern, Nyahongo, \& Røskaft, 2007; Lyamuya, Masenga, Fyumagwa, \& Røskaft, 2013; Masenga \& Mentzel, 2005).

A range of options exist for people attempting to decrease conflict with wildlife, including reducing the likelihood of attacks by using protective measures (such as livestock-guarding dogs and donkeys), electric fencing, improved construction of livestock enclosures, toxic collars, disruptive stimuli and other aversive techniques (Hodkinson, Davies-Mostert, Komen \& Snow, 2007; Marker, Dickman, \& Macdonald, 2005; Ogada, Woodroffe, Oguge, \& Frank, 2003; Ukio, 2010). Improvements in livestock husbandry, such as the employment of herders and the kraaling of stock (enclosure for livestock), have been shown to considerably reduce the rates of depredation by carnivores (Ogada, Woodroffe, Oguge, \& Frank, 2003). Livestock depredation promotes negative emotional sentiments towards conservation (Ikanda, 2009; Røskaft, Händel, Bjerke, \& Kaltenborn, 2007). It leads to indiscriminate persecution of wildlife, in the form of retaliatory killing in retribution for losses (Ikanda \& Packer, 2008; Kissui, 2008; Woodroffe \& Frank, 2005).

The cost of livestock predation is greater where people's livelihoods depend entirely on livestock keeping (Ogada, Woodroffe, Oguge, \& Frank, 2003). Losses due to depredation are common with cattle, sheep and goats (Inskip \& Zimmerman, 2009). Loss of a single domestic animal creates serious socio-economic problems to affected families (Ikanda, 2009; Nyahongo \& Røskaft, 2011). However, diseases have been reported to contribute to far more livestock losses than predation in some Tanzanian areas (Graham, Beckerman, \& Thirgood, 2005; Kissui, 2008; Nyahongo, 2007; Nyahongo \& Røskaft, 2011).

Predators may be attracted to feed on domestic stock when stock are taken to graze around protected areas or within their village areas; however, the number of livestock killed by predators per year per household has rarely been quantified. Ultimately, effective conflict resolution on livestock depredation requires a broad, many-sided and truly interdisciplinary approach. Conservation biologists must therefore move beyond examining the wider ecological, socio-economic and cultural conditions under which intense conflicts arise (Dickman, 2010). Therefore, this study intended to investigate the losses that local communities incur due to livestock depredation and analyse the economic effects these losses have on household income. We hypothesise that livestock losses due to depredation are higher in villages close to protected areas than in distant villages. We also hypothesised that household economic losses due to livestock depredation are higher in the villages close to the protected areas than in distant villages and that the losses due to larger carnivores are more serious in the villages close to the protected area because larger carnivores can only leave the protection of the park for short periods of time. Because diseases cause major losses in African livestock husbandry, we predicted that livestock losses due to diseases are higher in the villages close to the protected area due to frequent contact with wildlife. Finally, we tested the measures that people employ to avoid depredation.

\section{Methods}

\subsection{Study Area}

The study area is located in the north-eastern corner of Tanzania in the north-western region of Serengeti National Park (SNP) - (Figure 1). SNP covers a total area of $14,763 \mathrm{~km}^{2}$. The western Serengeti corridor extends westward to Lake Victoria $\left(1^{\circ} 30^{\prime}-2^{\circ} 30^{\prime}\right.$ and $\left.33^{\circ} 50^{\prime} \mathrm{S}-34^{\circ} 45^{\prime} \mathrm{E}\right)$. Rainfall in the Serengeti is seasonal and determined by large-scale weather patterns, modified by local topography (Pennycuick \& Norton-Griffiths, 1976). The rain normally falls in two periods; the short rains from November to February and the long rains from April to June. There is a rainfall gradient from the dry southwest plains to the wetter northwest plains. Rainfall increases from 514-688 mm per year in the southeast plains to $857-976 \mathrm{~mm}$ per year in the central woodlands and western corridor to $972-1100 \mathrm{~mm}$ per year in the north (Campbell \& Hofer, 1995). The monthly averages of the maximum temperatures in the western Serengeti fluctuate between $25{ }^{\circ} \mathrm{C}$ to $32{ }^{\circ} \mathrm{C}$ (Campbell \& Hofer, 1995). The minimum daily temperature ranges between $13^{\circ} \mathrm{C}$ and $19^{\circ} \mathrm{C}$. The people inhabiting this region are either 
agro-pastoralists or pastoralists. Serengeti National Park currently suffers a high degree of conflict between conservation priorities of the park and priorities of local communities (Hofer, Campbell, East, \& Huish, 1996; Loibooki, 1997). The human population of the western Serengeti is high and expected to increase due to high birth rates and immigration into villages adjacent to protected areas (Estes, Kuemmerle, Kushnir, Radeloff, \& Shugart, 2012; Hofer, Campbell, East \& Huish, 1996). The areas north and west of SNP are densely populated (> 70 people $/ \mathrm{km}^{2}$ ). The human population in the Mara Region in 2001 was approximately 1.37 million, growing at a rate of $2.9 \%$ per annum (URT, 2003). The main ethnic groups in the two districts are Ikoma, Sukuma, Nata, Ikizu, Jita and Kurya. Although most people are subsistence farmers, there are some ethnic differences in economic activities, which include fishing, livestock rearing, game meat hunting, and trading (Loibooki, 1997; Loibooki, Hofer, Campbell, \& East, 2002). Livestock rearing is for both meat and income (Kauzeni \& Kiwasila, 1994; Olsen, 1998). Husbandry is commonly practiced in the western Serengeti, and livestock includes cattle, goats, sheep and poultry, although a few households keep pigs and donkeys (Nyahongo, 2007).

\subsection{Data Collection Techniques}

Data for the current study were collected throughout the year from January to December 2010. Sampling included nine selected villages along a gradient of distance from the park. Three villages were located within a $10 \mathrm{~km}$ distance from the protected area (Robanda, Nyamakendo and Nattambisso), three villages were within a $40 \mathrm{~km}$ from the protected area (Butiama, Busegwe and Rwamkoma) and three villages were within a $80 \mathrm{~km}$ from the protected area (Ochuna, Makongro and Kowak) (Figure 1). Data for livestock depredation were collected through different techniques: key informant survey, group discussions, and questionnaires. The questionnaire interviews covered a total of 459 households that were randomly selected from the village and sub-village registers for interviews. We interviewed household heads, their wives or resident adults ( $\geqslant 18$ years old). The villages and sub-villages were picked based on a random-systematic selection. In terms of gender, $36.2 \%$ of the interviewed respondents were females and $63.8 \%$ were males. The questions were both close-ended and open-ended aimed at extracting the respondent's opinion in an open minded atmosphere. The questionnaire addressed socio-demographic variables including number of livestock owned, livestock depredation experiences, livestock depredation incidences, type of livestock depredated and wild animals responsible for the damage, estimates of livestock depredation, coping strategies against livestock depredation and livestock diseases experienced in the study area. The same data were recorded for the six selected villages. For each village, we selected ten households whose livestock were monitored for livestock depredation. We hired an enumerator in each village who recorded livestock predation data in the village and in other adjacent villages. 


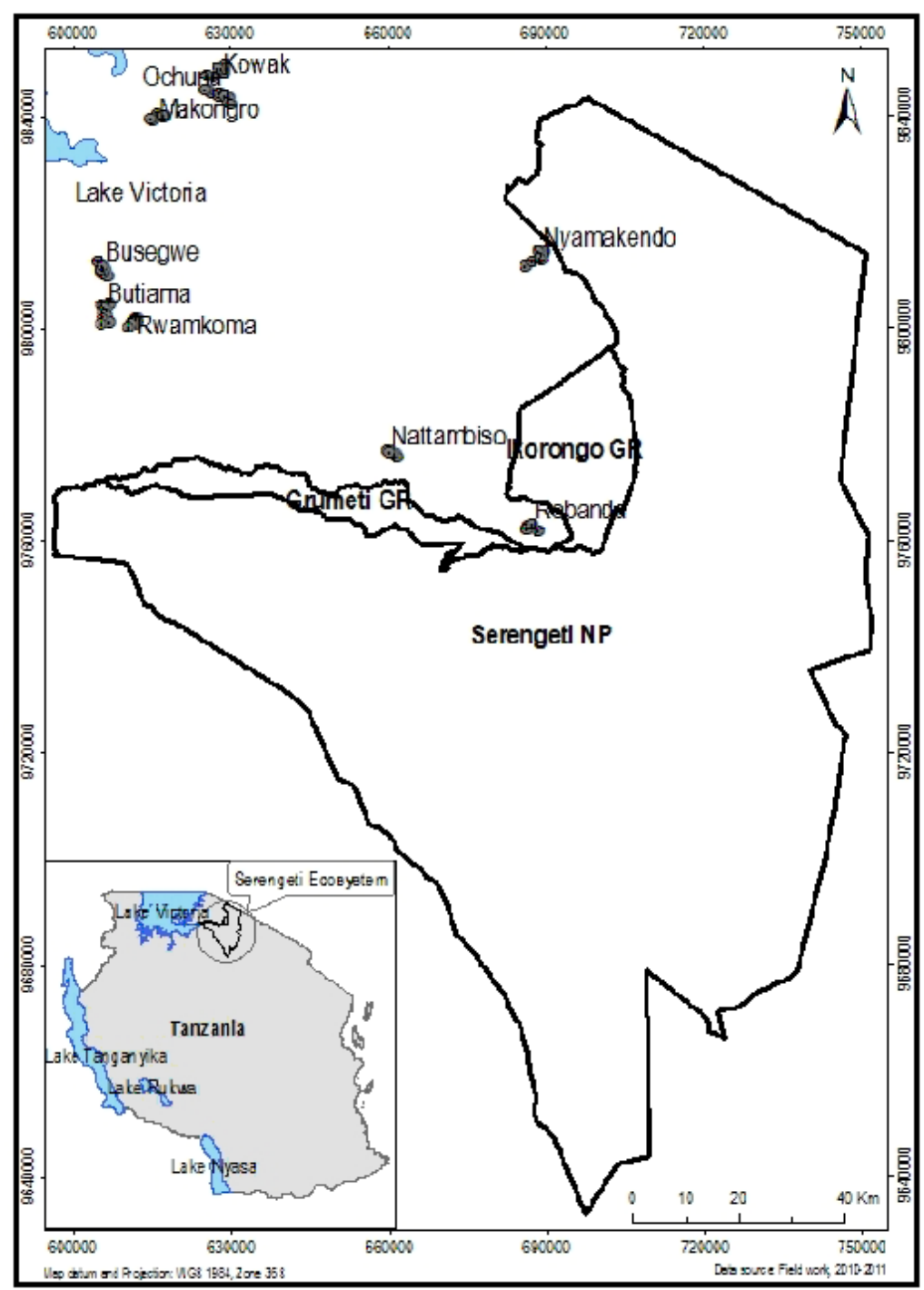

Figure 1. Map of study area showing Serengeti National Park, Grumeti and Ikorongo Game Reserves, Lake Victoria and the surveyed villages (Robanda, Nyamakendo, Nattambisso, Butiama, Busegwe, Rwamkoma,

Ochuna, Makongro and Kowak indicated with triangles)

\subsection{Data Analysis}

Statistical analyses were conducted using Statistical Package for the Social Sciences (SPSS, version 17). Pearson's Chi-square analyses were applied to test for the differences between independent variables including distance from the protected area (village within $10 \mathrm{~km}$ (closest villages), $40 \mathrm{~km}$ (medium villages) or $80 \mathrm{~km}$ (far away villages) and whether this influenced livestock depredation patterns in the study area, whether carnivore species involved in livestock depredation related to the distance of the village from the protected area, different methods used to protect livestock from being depredated by wild animals and the frequency of occurrence of livestock diseases. A Multiple response analysis was used to estimate loss cost of livestock depredation per household per year.

\section{Results}

\subsection{Livestock Depredation by Wild Animals}

The majority of respondents kept livestock $(85.2 \%, \mathrm{n}=452)$, and $58.4 \%(\mathrm{n}=385)$ of the respondents had experienced livestock depredation. The frequency of livestock depredation differed significantly among the surveyed villages along the gradient of distance from the park (Closest $=74.8 \%$; Medium $=62.8 \%$ and Far away $=41.6 \%$ ) (Pearson's Chi-square: $\chi^{2}=31.8$, d.f. $=2, \mathrm{P}<0.001$, Figure 2 ). 


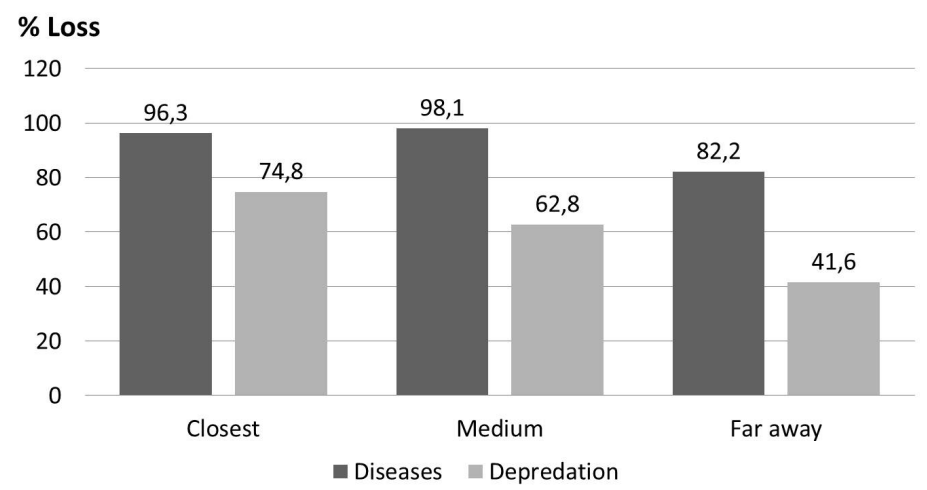

Figure 2. Percentage of households experiencing livestock disease losses and livestock depredation in relation to distances from the protected areas of the surveyed villages

\subsection{Wild Animals Involved in Livestock Depredation}

Wild animals involved in livestock depredation differed significantly among the surveyed villages (Pearson's Chi-square: $\chi^{2}=79.6$, d.f. $=8, \mathrm{P}<0.001$, Table 1). Spotted hyenas were reported to be the most destructive wild animals in all surveyed villages $(51.3 \%, \mathrm{n}=385)$, followed by other small carnivores and primates (mongoose, jackals, baboons) $(32.1 \%, \mathrm{n}=385)$, which were most destructive in the intermediate and farther villages. Other wild animals reported to kill livestock were hawks, leopards, lions, and wild dogs. Spotted hyenas were reported to kill all types of livestock from cattle to poultry (Table 2), while other large and medium sized carnivores were mainly reported to kill cattle or goats. Poultry were depredated by small carnivores and hawks while domestic dogs were reported to be depredated by hyenas and jackals (Table 2).

Table 1. Wild animals involved in livestock depredation based on distance from the protected area

\begin{tabular}{ccccccc}
\hline Villages & & \multicolumn{5}{c}{ Wild animals } \\
\cline { 2 - 6 } & & $\begin{array}{c}\text { Spotted } \\
\text { Hyena }\end{array}$ & $\begin{array}{c}\text { Small } \\
\text { Carnivores }^{\mathrm{x}}\end{array}$ & Hawks & Leopards & Lions / Wild dogs \\
\hline Closest & $\mathrm{N}$ & 85 & 14 & 6 & 12 & $12^{\mathrm{xx}}$ \\
& $\%$ & 65.9 & 10.9 & 4.7 & 9.3 & 9.3 \\
\multirow{5}{*}{ Medium } & $\mathrm{N}$ & 36 & 42 & 10 & 0 & 0 \\
& $\%$ & 40.9 & 47.7 & 11.4 & 0 & 0 \\
Far away & $\mathrm{N}$ & 55 & 54 & 16 & 1 & 0 \\
& $\%$ & 43.5 & 42.9 & 12.7 & 0.3 & 0 \\
Total & $\mathrm{N}$ & 176 & 110 & 32 & 13 & 3.5 \\
& $\%$ & 51.3 & 32.1 & 9.3 & 3.8 & \\
& & & & & & 0 \\
\hline
\end{tabular}

\footnotetext{
${ }^{\mathrm{x}}=$ Small Carnivores includes mongoose, jackals and baboons.

${ }^{\mathrm{xx}}=8$ cases of lions and 4 cases of wild dogs.
}

\subsection{Measures by Local Communities for Prevention of Livestock Depredation}

To prevent livestock depredation from wild animals, local communities around the Serengeti ecosystem use different methods. However, the methods widely used to protect livestock from being depredated by wild 
animals differed significantly by the distance of the village from the protected area (Pearson's Chi-square: $\chi^{2}=$ 14.4 d.f. $=6, \mathrm{P}=0.025$, Table 3 ). The most commonly used strategy to prevent livestock depredation was to build livestock enclosures (bandas) to protect livestock at night $(39.8 \%, \mathrm{n}=231)$, followed by the constant guarding of livestock with arrows and spears in the field when grazing $(35.5 \%, \mathrm{n}=231)$ and using guard dogs in the field and at night $(13.9, \mathrm{n}=231)$. Constant guarding of livestock with arrows and spears in the field when livestock are grazing was the most preferred protection method against depredation by livestock keepers in villages closest to the protected area. Building livestock enclosures (bandas) to protect livestock at night and the use of guard dogs were mostly used in the villages furthest away from the protected area (Table 3).

Table 2. Wild animals responsible for specific livestock depredated

\begin{tabular}{llllll}
\hline Responsible wild animals & \multicolumn{5}{l}{ Livestock depredated } \\
\cline { 2 - 6 } & Cattle & Goats & Sheep & Dogs & Poultry \\
\hline Spotted hyena & $\sqrt{ }$ & $\sqrt{ }$ & $\sqrt{ }$ & $\sqrt{ }$ & $\sqrt{ }$ \\
Leopard & $\sqrt{ }$ & & & & \\
Lion & $\sqrt{ }$ & & & & \\
Wild dog & & $\sqrt{ }$ & & & $\sqrt{ }$ \\
Small carnivores & & & $\sqrt{ }$ & $\sqrt{ }$ & $\sqrt{ }$ \\
Hawks & & & & & \\
\hline
\end{tabular}

$\overline{\mathrm{x}}=$ Small carnivores includes mongoose and jackals and baboons.

\subsection{Economic Loss Due to Livestock Depredation}

The estimated cost of depredation differed significantly among the villages along the gradient of distance from the protected area (ANOVA; $F=7.724$, d.f. $=2, P=0.001$, Table 4). The total estimated mean loss for the surveyed villages caused by livestock depredation was 47,094 Tshs (equivalent to $\$ 28.60$ USD) per household per year (Table 4). The villages located closest to the protected area reported to have the highest mean estimated loss $(71,293$ Tshs equivalent to $\$ 47.50$ USD) per household per year compared to other villages. The villages located far away from the protected area reported to have the lowest estimated loss $(29,066$ Tshs equivalent to $\$ 19.40$ USD) per household per year. The total mean number of depredated livestock was one cow, one goat, one dog and one sheep per household per year while the number of poultry was three per household (see Table 5). There were no records of depredated donkeys in the surveyed villages.

Table 3. Preventive measures to reduce livestock depredation in relation to distances from the protected area

\begin{tabular}{|c|c|c|c|c|c|c|}
\hline \multirow[t]{2}{*}{ Villages } & \multicolumn{6}{|c|}{ Preventing measures } \\
\hline & & $\begin{array}{l}\text { Building of } \\
\text { livestock } \\
\text { enclosures/ } \\
\text { bandas }\end{array}$ & $\begin{array}{ll}\text { Guarding } & \\
\text { livestock } & \text { with } \\
\text { arrows } & \text { and } \\
\text { spears } & \end{array}$ & $\begin{array}{l}\text { Guarding } \\
\text { with dogs }\end{array}$ & None & Total \\
\hline \multirow[t]{2}{*}{ Closest } & $\mathrm{N}$ & 30 & 38 & 8 & 10 & 86 \\
\hline & $\%$ & 34.9 & 44.2 & 9.3 & 11.6 & 100 \\
\hline \multirow[t]{2}{*}{ Medium } & $\mathrm{N}$ & 12 & 19 & 7 & 7 & 45 \\
\hline & $\%$ & 26.7 & 42.2 & 15.6 & 15.6 & 100 \\
\hline \multirow[t]{2}{*}{ Far away } & $\mathrm{N}$ & 50 & 25 & 17 & 8 & 100 \\
\hline & $\%$ & 50.0 & 25.0 & 17.0 & 8.0 & 100 \\
\hline
\end{tabular}


Table 4. Estimated cost of livestock depredation by wild carnivores per household per year

\begin{tabular}{ll}
\hline Village of respondent & $\begin{array}{l}\text { Estimated cost of livestock depredated (TShs) } \\
\text { Mean }(\mathrm{SD}) \mathrm{N}\end{array}$ \\
\hline Closest & $71,293.00( \pm 10.431) \mathrm{N}=55$ \\
Medium & $34,090.00( \pm 10.000) \mathrm{N}=38$ \\
Far away & $29,066.00( \pm 5.848) \mathrm{N}=46$ \\
Total & $47,094.00( \pm 9.719) \mathrm{N}=139$ \\
\hline
\end{tabular}

\subsection{Livestock Diseases}

Overall, $91 \%$ of respondents $(n=385)$ reported loss because of livestock disease. The frequency of livestock diseases differed significantly among the surveyed villages along the gradient of distance from the park (Pearson's Chi-square: $\chi^{2}=23.7$, d.f. $=2, \mathrm{P}<0.001$, Figure 2). The frequency of households that experienced livestock loss due to disease was highest in villages located close to the protected area (Figure 2). Ninety-six percent of respondents $(96.2 \%, \mathrm{n}=385)$ were reported to treat their livestock to cure them from different diseases.

Table 5. Number of livestock depredated per household per year along the distance from the protected area

\begin{tabular}{|c|c|c|c|c|c|c|}
\hline \multirow[t]{2}{*}{ Village } & & \multicolumn{5}{|c|}{ Number of livestock depredated } \\
\hline & & Cattle & Goats & Dogs & Sheep & Poultry \\
\hline \multirow[t]{3}{*}{ Closest } & Mean & 1.5 & 1.7 & 1.3 & 1.8 & 3.4 \\
\hline & $\mathrm{N}$ & 18 & 19 & 15 & 17 & 65 \\
\hline & SD & 0.78 & 0.87 & 0.45 & 1.03 & 2.82 \\
\hline \multirow[t]{3}{*}{ Medium } & Mean & 1.0 & 1.1 & 1.0 & 1.0 & 3.4 \\
\hline & $\mathrm{N}$ & 3 & 8 & 5 & 1 & 43 \\
\hline & SD & 0.00 & 0.35 & 0.00 & . & 3.46 \\
\hline \multirow[t]{3}{*}{ Far away } & Mean & 1.1 & 1.1 & 1.0 & 1.2 & 3.0 \\
\hline & $\mathrm{N}$ & 8 & 23 & 2 & 19 & 56 \\
\hline & SD & 0.35 & 0.34 & 0.00 & 0.37 & 1.92 \\
\hline \multirow[t]{3}{*}{ Total } & Mean & 1.3 & 1.4 & 1.2 & 1.4 & 3.3 \\
\hline & $\mathrm{N}$ & 29 & 50 & 22 & 37 & 164 \\
\hline & SD & 0.67 & 0.66 & 0.39 & 0.80 & 2.74 \\
\hline
\end{tabular}

\section{Discussion}

\subsection{Livestock Depredation}

As reported in many other studies (Kangwana, 1995; Kolowski \& Holekamp, 2006; Sillero-Zubiri \& Laurenson, 2001), the findings of this study suggest that the distance of the villages from the protected area is an important factor in determining the extent of livestock depredation by wild animals. Our results confirm our hypothesis that the closest villages to the protected area experience the highest frequencies of livestock depredation, and by the larger predators, such as lions and leopards. This is because a higher population of large carnivore species are 
found in the villages located close to the protected area (Holmern, Mkama, Muya, \& Røskaft, 2006). Additionally, during the dry season when there is a shortage of pastures in village areas, livestock keepers may graze their herds near or inside protected areas, which will expose livestock to predators.

\subsection{Wild Animals Involved in Livestock Depredation}

Many other studies in Tanzania (Holmern, Mkama, Muya, \& Røskaft, 2006; Ikanda \& Packer, 2008; Kissui, 2008; Nyahongo, 2007) have reported that the size of predators determines the size of the prey they depredate. Different wild animals were therefore involved in livestock depredation among the surveyed villages. Spotted hyena was reported to be the most destructive wild animal in all surveyed villages followed by small carnivores, including baboons, which were especially destructive in villages further away from the protected area. Hyenas were reported to be responsible for all types of livestock depredation, from cattle to poultry. Poultry were mainly depredated by small carnivores (mongoose, jackals and baboons), as well as hawks, due to their size and the size of the predators in question.

\subsection{Measures Taken by Local Communities for Deterring Crop Raiders}

The results indicated that methods used to protect livestock from being depredated by wild animals differed significantly depending on the distance of the village from the protected area. Livestock keepers in villages located close to the protected area preferred constant guarding with arrows and spears during grazing. This may be because livestock keepers closer to the park continue moving with their livestock in pastures and sometimes engage in bushmeat hunting. The building of livestock enclosures (bandas) to protect livestock during the night and the use of guard dogs was mostly preferred in the villages furthest away from the protected area. This observation indicates that livestock keepers in farther villages might have insufficient grazing area similar to those near the protected area who sometimes graze illegally inside the park. Additionally, most local communities in the western Serengeti are agro-pastoralist; therefore, livestock keepers in the farther villages have no alternative grazing areas (especially during the farming season which requires a large portion of grazing land), forcing livestock keepers to graze relatively large numbers of livestock in small portions that are not cultivated.

\subsection{Economic Loss}

Livestock depredation causes significant economic losses to households in the local communities surrounding the protected area. The total estimated mean loss by livestock depredation is higher compared to that reported in the same region by Nyahongo and Røskaft (2011). However, our study included poultry and domestic dogs which were not considered in Nyahongo and Røskaft's comparative study. The inclusion of poultry and domestic dogs might have elevated the level of predation or the numbers of predators might have increased in the study area. Our data cannot confirm the latter. The villages located closest to the protected area were reported to have the highest loss which may be because closer villages from the protected area have a higher number of large carnivores compared to the villages located farther away from the protected area. This type of livestock loss has a significant economic impact on rural communities (Hazzah, 2006; Ikanda, 2009). Loss of a single domestic animal to wildlife may create serious socio-economic consequences to affected families because livestock act as social capital and a sign of wealth in rural communities.

\subsection{Livestock Diseases}

Livestock disease was the most important factor responsible for livestock losses in the western Serengeti (Nyahongo \& Røskaft, 2011). The highest frequencies of deaths due to diseases were as hypothesised, experienced in villages located closest to the protected area. This may be due to local communities living close to the protected area who illegally graze their livestock inside the park, due to the shortage of pastures and water sources in their areas, especially during dry seasons. Interactions between wild and domestic animals increase the risk of disease transmission (Gortázar, Ferroglio, Höfle, Frölich, \& Vicente, 2007). Encroachment of protected area for grazing might result in wildlife habitat degradation. Degradation and fragmentation are the main anthropogenic factors associated with the emergence of diseases in wildlife (Acevedo-Whitehouse \& Duffus, 2009; Hudson, Rizzoli, Grenfell, Heesterbeek, \& Dobson, 2002).

\section{Conclusions and Recommendations}

\subsection{Conclusions}

The results obtained from this study on livestock depredation by wild animals in the Serengeti Ecosystem revealed the following:

Livestock depredation differed significantly among the surveyed villages along the gradient of distance from the 
park, with the lowest depredation in the farthest village from Serengeti National Park.

The spotted hyena was reported to be the most destructive wild animal in all surveyed villages followed by small carnivores, which were especially destructive in the medium and farthest villages.

Local communities around protected areas use different deterring methods to prevent livestock depredation by wild animals. The most common strategy used to prevent livestock depredation was to build livestock enclosures (bandas) to protect livestock at night, followed by constant guarding of livestock with bows and arrows when grazing in the field.

Livestock depredation causes a significant economic loss in households with villages located closest to the protected area having the highest household economic losses.

Livestock diseases were the main cause of livestock mortality. There were a higher percentage of households that experienced livestock loss due to disease in villages located closest to the protected area.

\subsection{Recommendations}

To reduce livestock depredation in the study area, conservation stakeholders should support efforts of local communities to improve their bomas. Education to improve livestock husbandry skills is highly recommended. As diseases are reported by the majority of respondents to be the main cause of livestock loss in the area; we recommend that veterinary units be staffed with well-trained personnel, adequate facilities and substantial operational budgets to enable them to provide quality service to control, prevent, or eliminate livestock diseases. Also, not only villagers near protected areas, but also any residents, should be helped by veterinary units. There is a need for a strong and effective collaboration among conservationists, local communities, governments, and health agencies to control these diseases. Finally, we recommend an integrated study on livestock and wildlife diseases and their impact on household economies of local communities.

\section{Acknowledgements}

We would like to thank the Wildlife Division (WD), and the Ministry of Natural Resources and Tourism for all assistance. In addition, we would like to thank the Tanzania Wildlife Research Institute (TAWIRI) for granting us permission to conduct this research and together with Norwegian University of Science and Technology (NTNU) for funding the data collection. We are also grateful to Tanzania National Parks (TANAPA) for allowing us to stay and work in Serengeti National Park. Finally, we thank the district and village leaders and our field assistants, all of whom contributed to the completion of this important study.

\section{References}

Acevedo-Whitehouse, K., \& Duffus, A. L. (2009). Effects of environmental change on wildlife health. Philosophical Transactions of the Royal Society B, Biological Sciences, 364, 3429-3438. http://dx.doi.org/10.1098/rstb.2009.0128

Baldus, R. D. (2004). Lion conservation in Tanzania leads to serious human-lion conflicts: with a case study of a man-eating lion killing 35 people. Wildlife Division.

Campbell, K., \& Hofer, H. (1995). People and wildlife: Spatial dynamics and zones of interaction. In A. R. E. Sinclair, \& P. Arcese (Eds.), Serengeti II: Dynamics, management and conservation of an ecosystem (pp. 534-570). Chicago, III: The University of Chicago Press.

Dickman, A. J. (2008). Investigating key determinants of conflict between people and wildlife, particularly large carnivores, around Ruaha National Park, Tanzania. University College.

Dickman, A. J. (2010). Complexities of conflict: the importance of considering social factors for effectively resolving human-wildlife conflict. Animal Conservation, 13, 458-466. http://dx.doi.org/10.1111/j.1469-1795.2010.00368.x

Estes, A. B., Kuemmerle, T., Kushnir, H., Radeloff, V. C., \& Shugart, H. H. (2012). Land-cover change and human population trends in the greater Serengeti ecosystem from $1984-2003$. Biological Conservation, 147, 255-263. http://dx.doi.org/10.1016/j.biocon.2012.01.010

Gortázar, C., Ferroglio, E., Höfle, U., Frölich, K., \& Vicente, J. (2007). Diseases shared between wildlife and livestock: A European perspective. European Journal of Wildlife Research, 53, 241-256. http://dx.doi.org/10.1007/s10344-007-0098-y

Graham, K., Beckerman, A. P., \& Thirgood, S. (2005). Human-predator-prey conflicts: Ecological correlates, prey losses and patterns of management. Biological Conservation, 122, 159-171. http://dx.doi.org/10.1016/j.biocon.2004.06.006 
Hazzah, L. (2006). Living among lions (Panthera leo): Coexistence or killing? Community attitudes towards conservation initiatives and the motivations behind lion killing in Kenyan Maasailand. University of Wisconsin.

Hodkinson, C., Davies-Mostert, H. T., Komen, H., \& Snow, T. (2007). Predators and farmers. Endangered Wildlife Trust.

Hofer, H., Campbell, K. L. I., East, M. L., \& Huish, S. A. (1996). The impact of game meat hunting on target and non-target species in the Serengeti. In J. Taylor, \& N. Dunstone (Eds.). The exploitation of mammal populations (pp. 117-146). London, UK: Chapman and Hall. http://dx.doi.org/10.1007/978-94-009-1525-1_9

Holmern, T., Mkama, S. Y., Muya, J., \& Røskaft, E. (2006). Intraspecific prey choice of bushmeat hunters outside the Serengeti National Park, Tanzania: A preliminary analysis. African Zoology, 41(1), 81-87. http://dx.doi.org/10.3377/1562-7020(2006)41\%5B81:IPCOBH\%5D2.0.CO;2

Holmern, T., Nyahongo, J. W., \& Røskaft, E. (2007). Livestock loss caused by predators outside the Serengeti National Park, Tanzania. Biological Conservation, 135(4), 534-542. http://dx.doi.org/10.1016/j.biocon.2006.10.049

Hudson, P. J., Rizzoli, A., Grenfell, B. T., Heesterbeek, H., \& Dobson, A. P. (2002). The ecology of wildlife diseases. Oxford: UK Oxford University Press.

Ikanda, D., \& Packer, C. (2008). Ritual vs. retaliatory killing of African lions in the Ngorongoro Conservation Area, Tanzania. Endangered Species Research , 6, 67-74. http://dx.doi.org/10.3354/esr00120

Ikanda, D. K. (2009). Dimensions of a human-lion conflict: the ecology of human predation and persecution of African lions Panthera leo in Tanzania PhD. Department of Biology, Norwegian University of Science and Technology.

Inskip, C., \& Zimmerman, A. (2009). Human-felid conflict: a review of patterns and priorities worldwide. Oryx, 43(1), 18-34. http://dx.doi.org/10.1017/S003060530899030X

Kajembe, G. C., Mayeta, L., Nduwamungu, J., \& Katani, J. Z. (2005). Resource use conflict management in Mpanga/Kipengere Game Reserve, Iringa, Tanzania. Fifth TAWIRI Scientific Conference on "People and Wildlife: Promoting Conservation While Balancing Needs, Impala Hotel, Arusha, 2005" (pp. 248-264). Tanzanua Wildlife Research Institute.

Kangwana, K. (1996). Assessing the impact of human-elephant interactions. In K. Kangwana, (Ed.) Studying elephants. AWF Technical Handbook No.7 (pp. 1-178). Nairobi: African Wildlife Foundation.

Kangwana, K. F. (1995). Human-elephant conflict: The challenge ahead. Pachyderm, 19, 11-14.

Kaswamila, A. (2009). Human - wildlife conflicts in Monduli District, Tanzania. International Journal of Biodiversity Science \& Management, 5(4), 199-207. http://dx.doi.org/10.1080/17451590903557526

Kauzeni, A. S., \& Kiwasila, H. L. (1994). Serengeti regional conservation strategy: a socio economic study. Institute of Resource Assessment, University of Dar Es Salaam.

Kent, V. T. (2011). The status and conservation potential of carnivores in semi-arid rangelands, Botswana the Ghanzi Farmlands: A case study. Durham University.

Kissui, B. M. (2008). Livestock predation by lions, leopards, spotted hyenas, and their vulnerability to retaliatory killing in the Massai Steppe, Tanzania. Animal Conservation, 11, 422-432. http://dx.doi.org/10.1111/j.1469-1795.2008.00199.x

Kolowski, J. M., \& Holekamp, K. E. (2006). Spatial, temporal, and physical characteristics of livestock depredations by large carnivores along a Kenyan reserve border. Biological Conservation, 128(4), 529-541. http://dx.doi.org/10.1016/j.biocon.2005.10.021

Kushnir, H., Leitner, H., Ikanda, D., \& Packer, C. (2010). Human and Ecological Risk Factors for Unprovoked Lion Attacks on Humans in Southeastern Tanzania. Human Dimensions of Wildlife, 15(5), 315-331. http://dx.doi.org/10.1080/10871200903510999

Loibooki, M. (1997). People and poaching: the interactions between people and wildlife in and around Serengetinational park. University of Reading, UK.

Loibooki, M., Hofer, H., Campbell, K. L. I., \& East, M. L. (2002). Bushmeat hunting by communities adjacent to the Serengeti National Park, Tanzania: the importance of livestock ownership and alternative sources of 
protein and income. Environmental Conservation, 29(3), 391-398. http://dx.doi.org/10.1017/S0376892902000279

Lyamuya, R., Masenga, E., Fyumagwa, R., \& Røskaft, E. (2013). Human-carnivore conflict over livestock in the eastern part of the Serengeti ecosystem, with special emphasis on African wild dogs. Oryx in the press.

Løe, J., \& Røskaft, E. (2004). Large carnivores and human safety: A review. Ambio, 33(6), 283-288. http://dx.doi.org/10.1579/0044-7447-33.6.283

Marker, L. L., Dickman, A. J., \& Macdonald, D. W. (2005). Perceived effectiveness of livestock- guarding dogs placed on Namibian farms. Rangeland Ecology and Management, 58, 329-336. http://dx.doi.org/10.2111/1551-5028(2005)058\%5B0329:PEOLDP\%5D2.0.CO;2

Masenga, H. E., \& Mentzel, C. (2005). The African wild dogs (Lycaon pictus); Preliminary results from a newly established population in Serengeti-Ngorongoro ecosystem, northern Tanzania. Proceedings of fifth annual TAWIRI scientific conference Arusha, Arusha, Tanzania, 2005 (pp. 8). Tanzania Wildlife Research Institute.

Nyahongo, J. W. (2007). Depredation of livestock by wild carnivores and illegal utilization of natural resources by humans in the Western Serengeti PhD. Department of Biology, Norwegian University of Science and Technology.

Nyahongo, J. W., \& Røskaft, E. (2011). Assessment of livestock loss factors in the Western Serengeti, Tanzania. In A. Kaswamila (Ed.), Natural Resource Management (pp. 155-163). Rijeka, Croatia: Intech.

Ogada, M. O., Woodroffe, R., Oguge, N. O., \& Frank, L. G. (2003). Limiting depredation by African carnivores: the role of livestock husbandry. Conservation Biology, 17(6), 1521-1530. http://dx.doi.org/10.1111/j.1523-1739.2003.00061.x

Ogutu, J. O., Bhola, N., \& Reid, R. (2005). The effects of pastoralism and protection in the density distribution of carnivores and their prey in Mara Ecosystem of Kenya. Journal of Zoology, London, 265, 281-293. http://dx.doi.org/10.1017/S0952836904006302

Olsen, A. K. E. (1998). Overview of the communities surrounding the Ikorongo/Grumeti Game Reserves. Ministry of Natural Resources and Tourism.

Packer, C., Ikanda, D., Kissui, B., \& Kushnir, H. (2005). Lion attacks on humans in Tanzania - Understanding the timing and distribution of attacks on rural communities will help to prevent them. Nature, London, 436(7053), 927-928. http://dx.doi.org/10.1038/436927a

Pennycuick, L., \& Norton-Griffiths, M. (1976). Fluctuation in the rainfall of the Serengeti ecosystem, Tanzania. Journal of Biogeography, 3, 125-140. http://dx.doi.org/10.2307/3038141

Quigley, H., \& Herrero, S. (2005).Characterization and prevention of attacks on humans. In R. Woodroffe, S. Thirgood, \& A. Rabinowitz (Eds.), People and wildlife: Conflict or coexistence? (pp. 27-48). Cambridge, UK: Cambridge University Press.

Røskaft, E., Händel, B., Bjerke, T., \& Kaltenborn, B. P. (2007). Human attitudes towards large carnivores in $\begin{array}{llll}\text { Norway. } \quad \text { Wildlife } & \text { Biology, } & 13(2), & 172-185 .\end{array}$ http://dx.doi.org/10.2981/0909-6396(2007)13\%5B172:HATLCI\%5D2.0.CO;2

Sillero-Zubiri, C., \& Laurenson, M. K. (2001). Interactions between carnivores and local communities: Conflict or coexistence? In J. L. Gittleman, S. M. Funk, W. D. MacDonald, \& R. K. Wayne (Eds.). Carnivore conservation. (pp. 107-122). Cambridge, UK: Cambridge University Press.

Sitati, N. W., Walpole, M. J., \& Leader-Williams, N. (2003). Predicting spatial aspects of human-elephant conflict. Journal of Animal Ecology, 20, 667-677.

Thirgood, S., Woodroffe, R., \& Rabinowitz, A. (2005). The impact of human-wildlife conflict in human lives and livelihood. In R. Woodroffe, S. Thirgood, \& A. Rabinowitz (Eds.). People and wildlife, Conflict or coexistence? (pp. 13-16). Cambridge, UK: Cambridge University Press.

Ukio, I. G. (2010). Husbandry practices and mitigation of human-carnivore conflicts. A case study of the Maasai Steppe, Tanzania. School of Environmental Sciences, University of KwaZulu-Natal, .

URT. (2003). Population and housing censuses. In P. S. O. P. C. (Ed.), Bureau of Statistics. Dar es Salaam, Tanzania: United Republic of Tanzania, Government Printer.

Woodroffe, R., \& Frank, L. G. (2005). Lethal control of African lions (Panthera leo): local and regional population impacts. Animal Conservation, 8, 91-98. http://dx.doi.org/10.1017/S1367943004001829 


\section{Copyrights}

Copyright for this article is retained by the author(s), with first publication rights granted to the journal.

This is an open-access article distributed under the terms and conditions of the Creative Commons Attribution license (http://creativecommons.org/licenses/by/3.0/). 